\title{
Numerical study on reservoir sediment management through adding excavated sediment downstream of dams in Japan
}

\author{
Sameh Kantoush ${ }^{1, *}$, Takamasa Suzuki $^{2}$, Yasuhiro Takemon ${ }^{1}$, Kamal El kadi Abderrezzak ${ }^{3}$, \\ Riadh $\mathrm{Ata}^{3}$, Tetsuya Sumi ${ }^{1}$, and Mohamed Saber ${ }^{1}$ \\ ${ }^{1}$ Disaster Prevention Research Institute, Kyoto University, Uji, Japan \\ ${ }^{2}$ Shizuoka Prefectural Government, Shizuoka, Japan \\ ${ }^{3}$ EDF R\&D, National Laboratory for Hydraulics and Environment, Chatou, France
}

\begin{abstract}
Dam related issues have become preoccupying, with raising concerns about detrimental environmental impacts and sedimentation in reservoirs. Reduction of the Ayu-fish production is due to increasing turbidity and decreasing coarse sediment supply by dams in the Tenryu River, Japan. The paper summarizes various case studies on excavated sediment supply in Japan and a case of numerical study to evaluate the effect of the supplied sediment on the spawning redds of Ayu-fish in the Tenryu River. Results of numerical simulations show that under the present management scheme of non-supplied sediment from the upstream dams, suitable spawning redds are formed on sandbars at the confluence instead of riffles. However, field surveys indicate that riffles with newly deposited sediment are more suitable for fish spawning.
\end{abstract}

\section{Sediment management techniques in Japanese reservoirs}

In Japan, there are more than 2700 operating dams, more than $15 \mathrm{~m}$ in height with median age of 61 years. Among them, 900 dams have reservoir volumes larger than $1.0 \mathrm{Mm}^{3}$. The aging of dams and continuous loss of water storage capacity due to sedimentation, coupled with increasing environmental needs, will cause growing concerns on several fronts: social, economic, and environmental [1, 2, 3, 4]. Japan is a world leader in the number of implemented sediment management techniques by flushing, sluicing, dredging/excavating, and bypassing. Figure 1 classifies the range of techniques that have been implemented in 900 Japanese reservoirs. Supplying the excavated sediment is the most dominant technique to recover reservoir function and restore the river ecosystem [5].

\subsection{Excavated/dredged sediment supply projects in Japan}

The technique consist in excavating or dredging sediments and placing them just below the dam or distributing them at various locations along the river banks. Then, the supplied

*Corresponding author: kantoush.samehahmed.2n@kyoto-u.ac.jp 
sediments are transported (eroded and deposited) along the riverbed by natural or artificial flushing flow. This method is win-win for recovering original functions of reservoir and restoring original natural riverbed state. However, in order to sustain the downstream ecological functionality, we must design optimal sediment volumes and grain size distribution, as they are recognized as key factors for a successful management to create and maintain physical habitats, aquatic and riparian ecosystems [6].

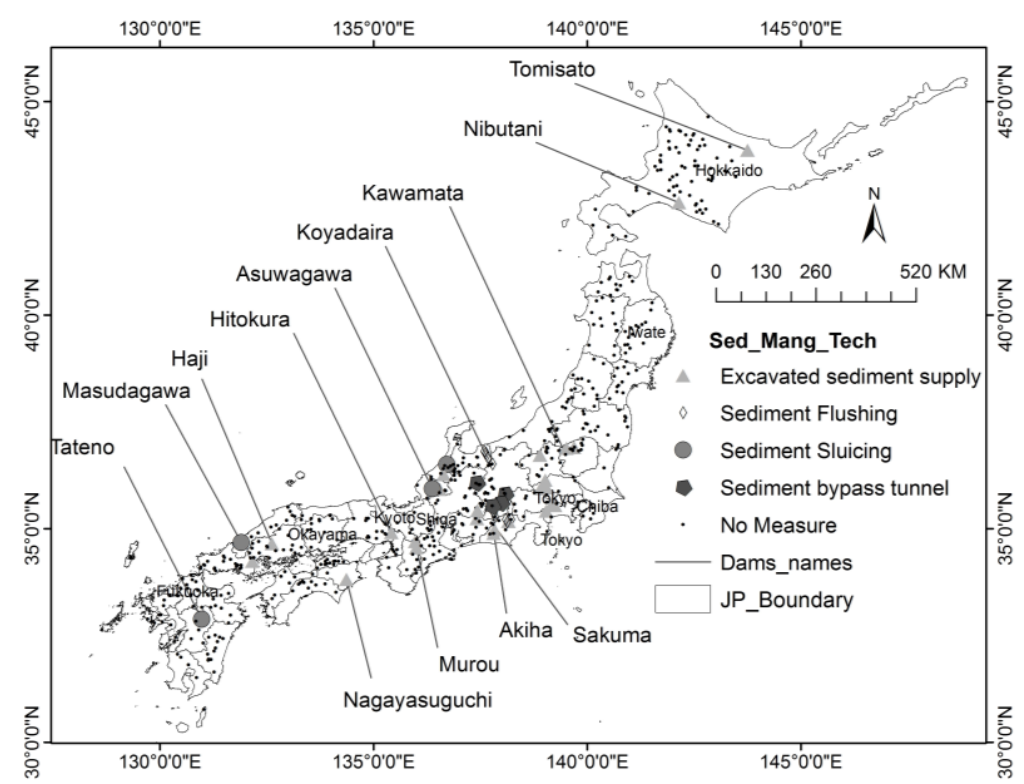

Fig. 1. Classification of sediment management techniques for storage reservoirs in Japan

In Japan, every year, limited sediment volumes are excavated and supplied below more than 27 dams (Figure 2). Detailed monitoring of pre- and post- sediment supply are carried out to analysis the impact of such technique on riverbed formation, riverbed materials, benthic organisms, and algae. As sediment supplied projects have different configurations of flow and sediment characteristics, some of these projects had positive impacts when supplied sediments are washed during high flows. On the other hands, some cases induced undesirable morphological and ecological consequences as well as significant channel adjustments that result in failure of the restoration project itself.

The following subsections introduce historical analysis for some of the ongoing sediment supply projects in Japanese rivers and reservoirs. A number of cases are presented covering the basic ideas of setting the necessary quantity of sediment downstream of dams to preserve the environment. Two dimensional numerical modelling in Ternyu River is presented with comparison with the field investigations.

\subsection{Volumes of supplied sediment below dams in Japan}

Designers of added dredged sediment projects are faced with challenges of estimating the necessary sediment volume and grain size distribution. In case of sediment management, it is necessary to find out appropriate combination of flushing flow and sediment supply which can meet demands of various river functions. Figure 2(a) shows the volumes ratio of supplied sediment for representative cases from Japan. The figure depicts that the percentage of supplied sediments volumes are very limited ranging between 0.1 to $10 \%$ of annual volumes of reservoir sedimentations. Figure 2(b) describes the condition of the downstream river as a 
function of supplied sediment volume and flushing flow discharges [7]. The conceptual figure shows that, the downstream river condition can be recovered from point 2 to point 3 by supplying an optimal sediment volume below dam. Moreover, combining the optimal sediment supply with flushing flow will enhance the downstream conditions by shifting from point 2 to point 4 and then point 5 (Fig. 2(b)). However, excess sediment supply will cause a negative impact on river conditions by shifting the condition from points 3 or 5 to point 6 .

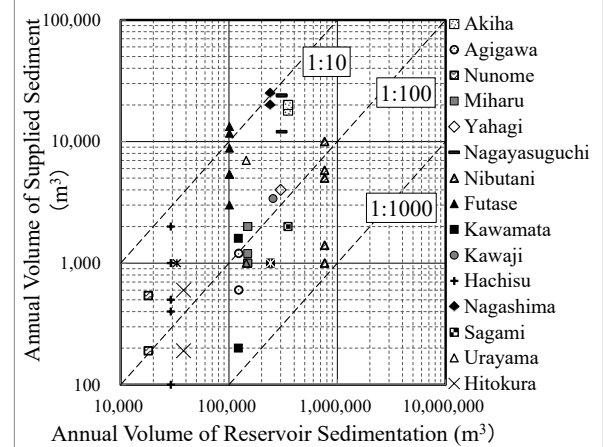

Fig. 2. (a) Volumes of supplied sediment

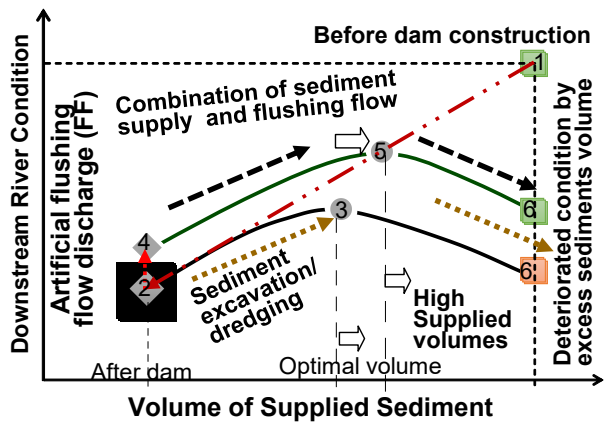

(b) Concept of sediment supply and river conditions

\subsection{Grain size distributions and placement methods of supplied sediment}

The crucial issue is to determine how to supply the sediment, at what grain sizes and percentage of fine sediment. Figure $3(\mathrm{a}, \mathrm{b})$ show the grain size distributions and pictures of the supplied sediments (low flow or point bar stockpiles for some of excavated and supplied sediment projects). In Miharu and Nunome dams, relatively fine material are dredged in the upstream secondary reservoirs for trapping nutrient rich sediments. Other projects consist in excavating coarse sediments from conventional check dams. Figure 3(a) shows that the supplied grain sizes in Akiha dam is mainly of coarse sand and gravel of $5.0 \mathrm{~mm}$ median diameter, ranging from $0.075 \mathrm{~mm}$ to $75 \mathrm{~mm}$ [8]. Figure 3 (b) shows various pictures of placed sediment during low flow level on the right banks as in Miharu, Murou and Nunome dams. Furthermore, in Nagayasuguchi dam the sediment is supplied directly from the road as a point bar stockpile as shown in Figure 3(b). The placed sediment will be distributed by the natural floods or artificial flushing in short duration and high magnitudes.

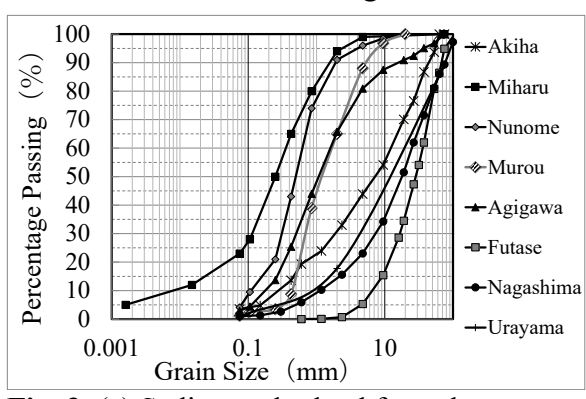

Fig. 3. (a) Sediment dredged from dam

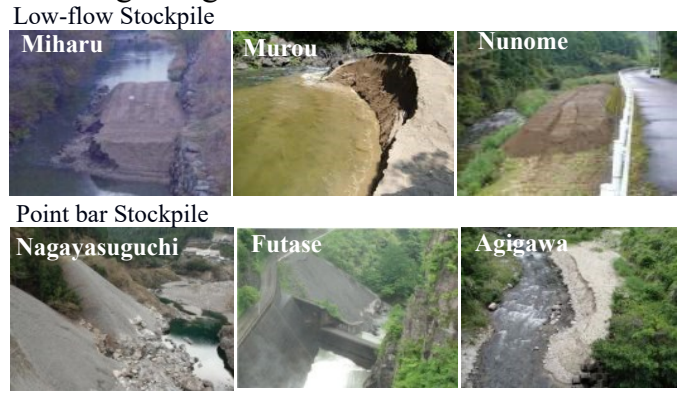

(b) Cases of supplied sediment placement \& injection

\section{Challenges of sediment supply in the Tenryu River}

The spawning redds of Ayu-fish, a representative fish in the Tenryu River, are focussed on for ecological evaluation of riverbed environment under present and assumed conditions of sediment supply through field surveys and $2 \mathrm{D}$ numerical simulations. The main purpose is to investigate the effects of increasing sediment supply and to determine the appropriate 
sediment management strategy. Generally Ayu-fish is known to spawn in riffles where the water is shallow and fast flowing. In the Tenryu River, however, Ayu-fish spawns at depths exceeding $1.0 \mathrm{~m}$ due to the deteriorating environment in the riffles [11]. Ayu-fish hide their eggs below the top layer of sand and gravel to protect them predation by other fishes [12]. The riverbed must be easy for Ayu-fish to dig, and the top layer of sand and gravel should have some gaps. Consequently, the riverbed environment is important when assessing the spawning redds of Ayu-fish. Although deep water is currently used for the spawning redds in the Tenryu River, once the riverbed environment is improved, Ayu-fish are expected to spawn in the shallow riffles with soft riverbeds composed of gravel being optimal for their spawning site.

\subsection{Field surveys}

The target study basin is the Tenryu River, which is located at the west of Shizuoka Prefecture, Japan. Five cascade dams have been constructed in Tenryu River basin. Out of the five dam series, Sakuma Dam has the largest reservoir which traps a massive volume of sediments of rate about 2.0 million $\mathrm{m}^{3} /$ year. The reservoir of Sakuma dam is located in the middle reaches of the Tenryu River (213 km in length), discharging its water into the Pacific Ocean via Akiha and Funagira dams. Because of the steep topography and fragile geology in the basin, rainfall storms and floods transport extremely large quantities of sediment in the river. As countermeasures, $1.1 \mathrm{Mm}^{3}$ of sediment are annually dredged and some portions are supplied to the downstream reach. The Dam Reorganization Project in the Tenryu River was developed to resolve the sediment issues due to the Sakuma Dam to establish a comprehensive sediment management strategy, and should be a turning point for future river management. To date, various studies on sediment removal methods from the Sakuma Dam have been conducted to assess the influence of supplying sediment [8]. However, suitable methods to predict the influence of supplying sediment to the river environment and rejuvenating the natural environment have yet to be established.

\subsection{Riverbed survey}

Field surveys on the riverbed environment were conducted in the lower reaches below Funagira dam in the Tenryu River (Fig. 4(a). Eight survey sites were established between the mouth of the river and approximately $20 \mathrm{~km}$ upstream, where Ayu-fish spawn their eggs. The river bed materials were collected in the top layer, the grain size distribution was measured, and resulted in the diameters with fairly uniform (Fig. 4(b)). The riverbed softness was measured by the cone penetration test using special devise composed of penetration cone, falling weight and scale. The riverbed softness is representative indicator of habitat suitability for spawning redds that defined by the penetration depth at a given number of blows through the falling weight. The results showed that the riffles of lower reaches at point 304 had the softest riverbed (Fig. 4(c)). The presence of Ayu-fish eggs was surveyed in November after the spawning season. Eggs were found in the section closest to the sea (approximately 3.4 $\mathrm{km}$ from the river mouth), which was a soft riverbed in strata lower than $20 \mathrm{~cm}$ from the river bottom (Fig. 4c: egg's bed).

\subsection{Monitoring of riverbed and hearing from fisheries cooperative}

The riverbed softness was higher upstream of a riffle at point 304 probably because riffle was newly created at the heavy runoff. In the Tenryu River high discharges exceeding $4,000 \mathrm{~m}^{3} / \mathrm{s}$ results in the sediment settlement in a mound shape upstream of a riffle. As the water level recedes, the gravel is gradually washed to downstream of the riffle, resulting in the riverbed 
with high riverbed softness [13]. Therefore, high discharge event is required for keeping up the soft riverbed in the riffle.
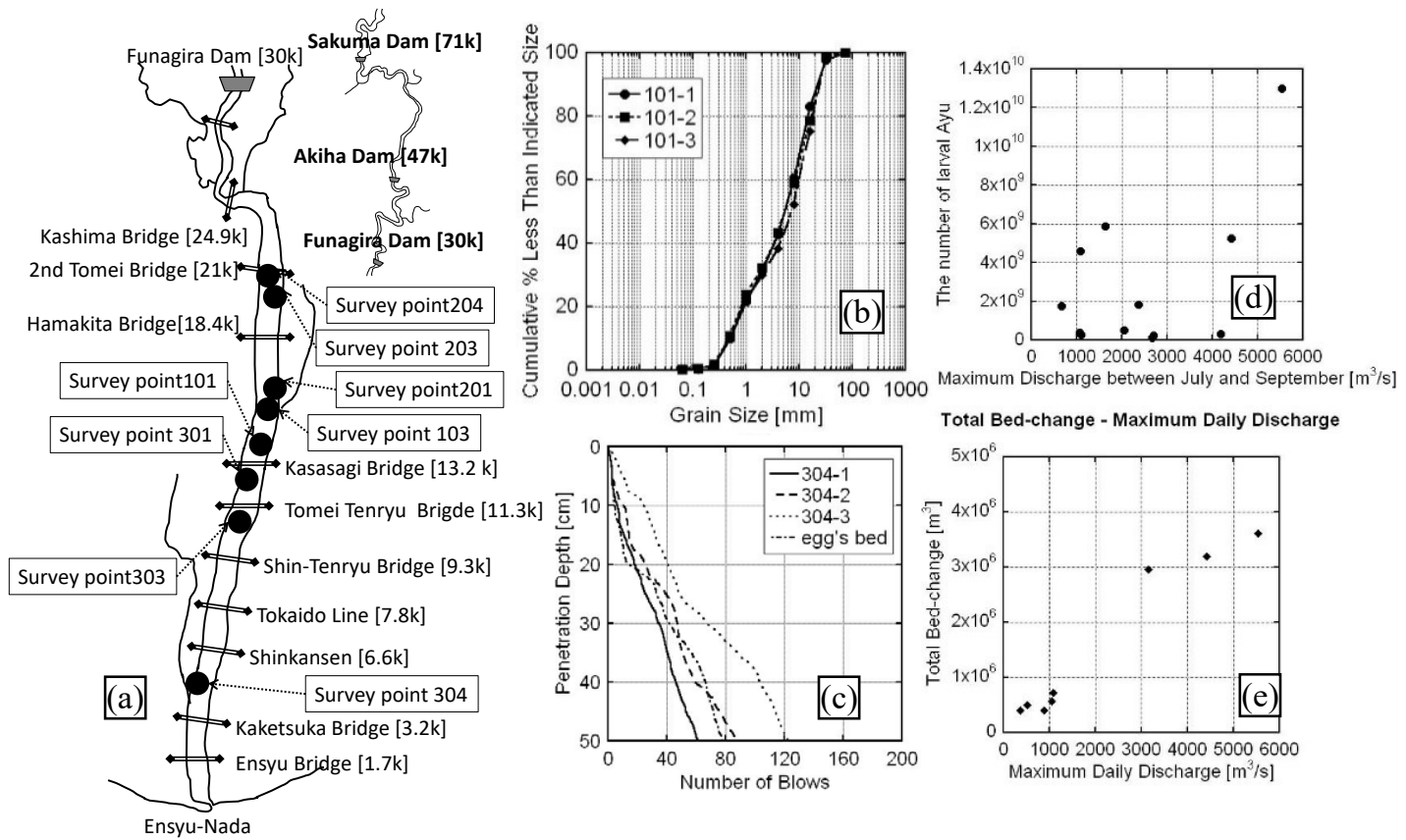

Fig. 4. Map view of Tenryu River and sampling points, riverbed grain size at survey points, bed softness and penetration depths, maximum discharges with number of Larval, and bed changes

The fisheries cooperative of the Tenryu River has monitored the annual changes in the Ayu-fish population by collecting the larvae of the fish drifting downstream just after hatching to the ocean at intervals of approximately 5 days from October to January every year [14]. Based on the monitoring data the number of drifting larvae in 2007 was remarkably high, and had declined rapidly in 2008 and 2009. The correlation between the maximum discharge from July to September and the number of drifting larvae is shown in Figure 4(d). This relationship is agreed well with the relations of total riverbed changes to the annual maximum discharge in the Tenryu River (Fig. 4(e)). Combining the results, it is concluded that the larger the flow rate, the more the riverbed changes creating the suitable spawning redds in riffles and leading to the higher reproductive success of Ayu-fish.

\section{Numerical modelling}

\subsection{Description of the model}

We employed the CCHE2D model [15], developed by the University of Mississippi, to simulate riverbed changes. CCHE2D is a depth-integrated 2D hydrodynamic and sediment transport model based on a variant of the finite element method. The model is used to predict river flow patterns and related bed and/or bank erosion for both uniform and non-uniform sediment transport. Numerical simulations have been performed to calibrate and validate different mesh sizes and model parameters (Fig. 5). The simulated area has a grid spacing of $20 \mathrm{~m}$ in flow direction and $10-15 \mathrm{~m}$ in the transverse direction. For turbulence closure, the 
Depth-Integrated Mixing Length Model is utilized of $0.1 \mathrm{~m}$. The sediment transport capacity, and the movable roughness are determined by Wu's [16] empirical formulas. The computed flow velocity were compared to measurements at the Hamakita Bridge $(18.40 \mathrm{~km})$ and Kasasagi Bridge (13.20 km) (Refer to Fig. 4(a)). The field measurements were made with a propeller flow velocity meter placed $0.5 \mathrm{~m}$ below the water surface. Figure 5 shows the computed and the measured velocities at Kasasagi Bridge (13.20 km from the estuary).
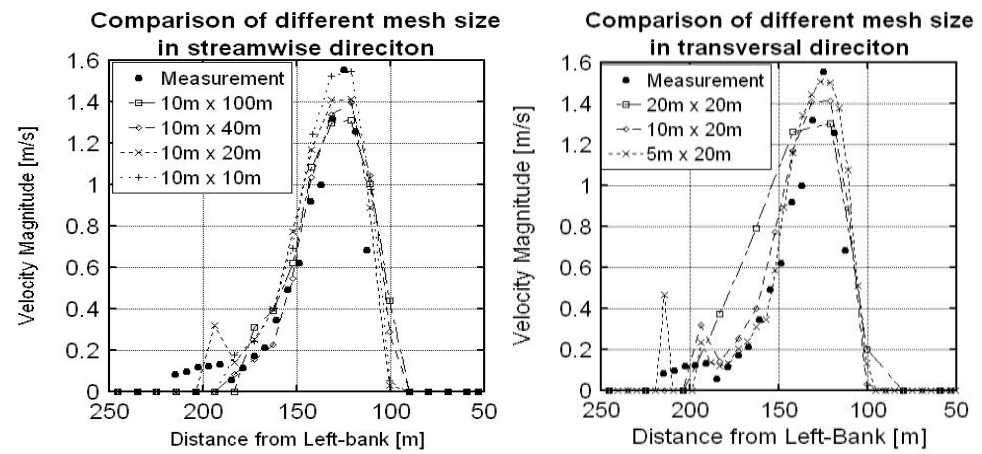

Fig. 5. Comparison of measured at $13.20 \mathrm{~km}$ and simulated velocity magnitudes of different mesh sizes

\subsection{Simulation results}

Bed topography measurements were obtained using a 3-D aerial laser profiler. Figures 6(a) and (b) show the modelled reaches bathymetries from $13 \mathrm{~km}$ to $17 \mathrm{~km}$ and from 17 to $21 \mathrm{~km}$, respectively. Figures 6(c) and (d) show the measured and simulated bed changes for calibration reach, with inflow rate more than $500 \mathrm{~m}^{3} / \mathrm{s}$ between February 2004 and November 2004. Deposition and erosion were reproduced well. For evaluation of the simulated results we assumed that area of sediment deposition would be soft riverbed. Because Ayu-fish prefer riffles of soft gravel riverbed for spawning redds, we judged the suitable spawning redds by overlaying the area of gravel bed, that of sediment deposition and of high current velocity.

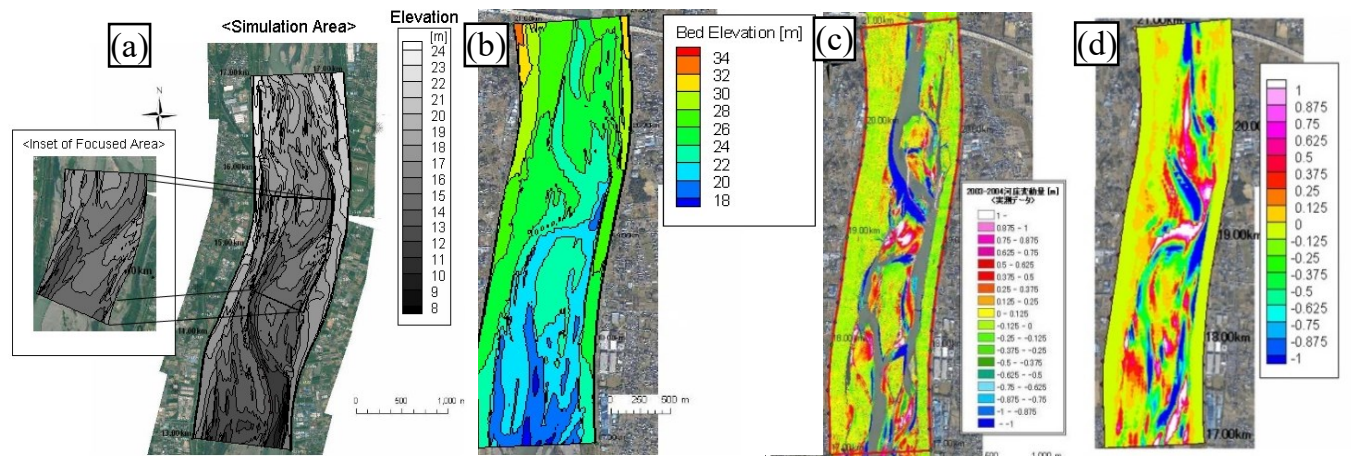

Fig. 6. (a) Simulated reach from $13 \mathrm{~km}$ to $17 \mathrm{~km}$, (b) simulated reach for calibration purposes from 17 $\mathrm{km}$ to $21 \mathrm{~km}$ between 2004.2-2004.11 (c) measured riverbed changes, (d) simulated riverbed changes

Approximately one year-long calculation was conducted with various inflow discharge of $6,000 \mathrm{~m}^{3} / \mathrm{s}$ and three sediment supply scenarios: no sediment supply (Case 1), only gravel supply (Case 5), and sand-gravel supply (Case 6). For each scenario, we identified areas with gravel riverbeds based on the grain diameter, areas with a high riverbed softness based on the amount of riverbed changes, and areas of riffles based on the flow velocity. Figure 7(b) shows the resulting average bed material diameter. For the current river management scheme 
where no sediment is supplied (Case 1, Fig. 7(a)), the riverbed changes significantly due to the upstream boundary conditions. A comparison of simulated changes in bed elevation with and without gravel supply is presented in Figure 8(a). In the current river management scheme, potential spawning redds are found at a confluence of a tributary and the main stream (Fig. 7(c)). When gravel is supplied from upstream (Case 5), one high flow of $6,000 \mathrm{~m}^{3} / \mathrm{s}$ (Fig. 8(c)) transport the gravel only about $2 \mathrm{~km}$ downstream, indicating that a long period of high discharges are necessary to supply gravel to spawning redds.
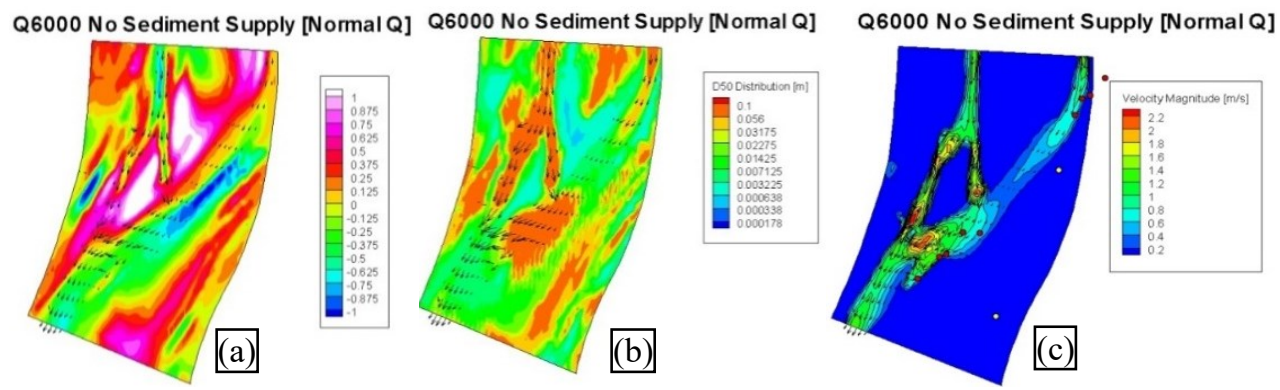

Fig. 7. Results of Case 1 scenario for (a) bed changes [m], (b) $\mathrm{D}_{50}[\mathrm{~m}]$, (c) velocity distribution

Consequently, solely supplying gravel from upstream will not have an immediate impact. Figure 8(b) shows the median grain size (D50) for Case 5. The figure demonstrates that in addition to supplying gravel from upstream, gravel must be directly supplied in the vicinity of spawning redds. Sediment should be supplied at an optimum locations based on the simulation results or suitable spawning areas. The flow velocity distribution in Figure 9(c) for Case 6 shows that after supply of sad the flow concentrated at the narrow side channel comparing with other cases.
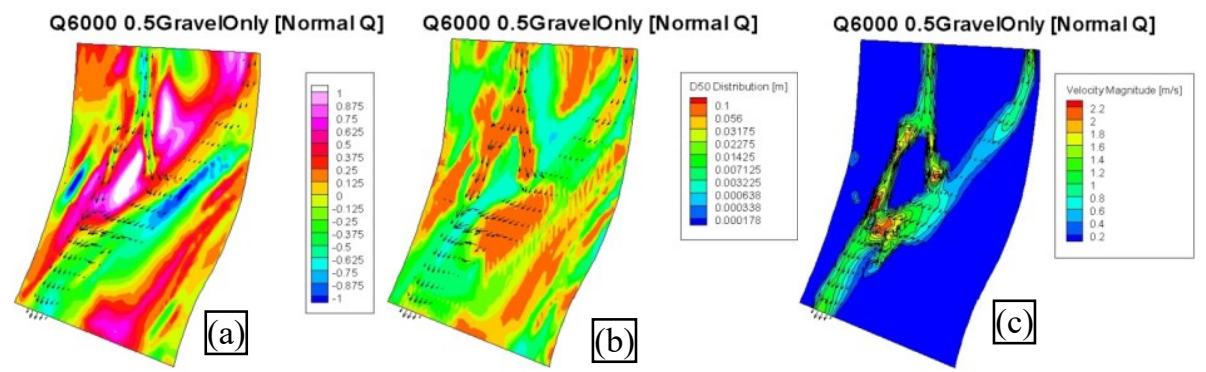

Fig. 8. Results of Case 5 scenario for (a) bed changes [m], (b) $\mathrm{D}_{50}[\mathrm{~m}]$, (c) velocity distribution
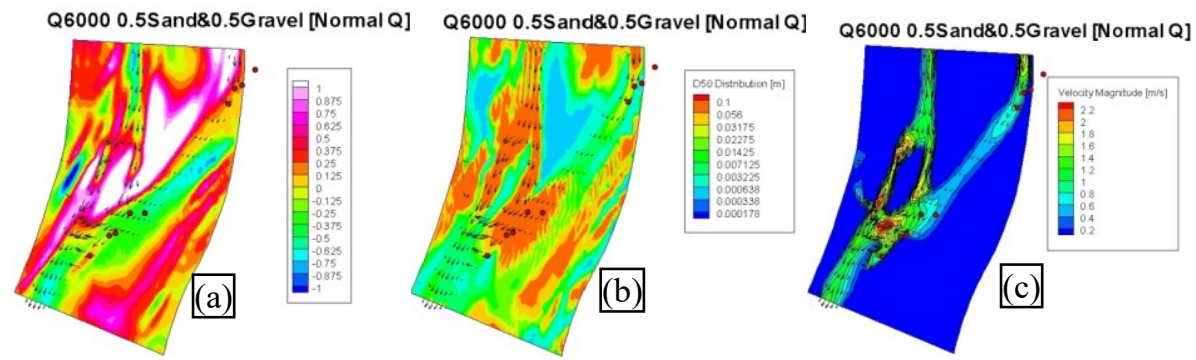

Fig. 9. Results of Case 6 scenario for (a) bed changes [m], (b) $\mathrm{D}_{50}[\mathrm{~m}]$, (c) velocity distribution $[\mathrm{m} / \mathrm{s}]$

The flow width become smaller due to sand deposition with different changes in bed elevation as shown in Fig. 9(a). A comparison of the simulated scenarios the median grain 
size (D50) at sandbars is larger in the Case as shown in Figure 9(b). A comparison of simulated changes in bed elevations in case of no sediment supply (Fig. 7(a)), no variation in bed changes at the main stream. However, relatively large variations are noticed at the side channel. In other scenarios, there is the same trend, and it can be said that the first riffle trap most of sediment deposition and at the side channel there are more gravel deposition indicate that river bed softness is high.

\section{Conclusions}

The effects of sediment supplies on the spawning environment for Ayu-fish were investigated via a review of past field studies at the Tenryu River. Newly formed riffles with gravel substrates were evaluated to be suitable for Ayu-fish spawning redds. Investigations to predict potential spawning areas using two-dimensional numerical modelling revealed that under the present management scheme of not supplying sediment from the upstream dam, suitable spawning redds would be formed not on riffles in the main channel, but on riffles in the secondary channel at the confluence with the main channel. Future projects include simulations to determine the impact of sediment supply conditions (i.e., location, quantity, etc.) on the number of soft riverbeds. Additionally, a more detailed investigation on the relationships between the formation of water channels on sandbanks and riverbed softness, which were investigated herein, will offer insight on the formation of Ayu-fish spawning redds due to the sediment supply and flow rate during floods.

\section{References}

1. G.L. Morris, J. Fan, Reservoir sedimentation hand-book (McGraw-Hill, 1998)

2. G. Annandale, Quenching the thirst: Sustainable water supply \&climate change (2013)

3. S.A. Kantoush, T. Sumi, Annuals of DPRI, Kyoto University 53B, (2010)

4. S. A. Kantoush, T. Sumi, and Y. Takemon, Int. water power \& dam, 38-45 (2011)

5. S.A. Kantoush, T. Sumi, A. Kubota, Proceedings of International Conference on Fluvial Hydraulics (River Flow 2010)

6. G. Ock, T. Sumi, Y. Takemon, Hydrological Research Letters 7, 54-59 (2013)

7. S.A. Kantoush, T. Sumi, Proceedings of The International Conference on Fluvial Hydraulics (River Flow 2016)

8. T. Sumi, M. Okano, Y. Takata, Proceedings of the 9th International Symposium on River Sedimentation, 1036-1043 (2004)

9. E. Battisacco, Replenishment of sediment downstream of dams erosion and transport processes (EPFL thesis No.7239, 2016)

10. F. Friedl, Laboratory experiments on sediment replenishment in gravel-bed rivers, (DISS. ETH No. 24826, 2017)

11. T. Suzuki, T. Sumi, Y. Takemon, K. Nakajima, Annuals of DPRI, 54B, 719-725 (2011)

12. I. Takahashi, K. Azuma, Book on Natural Ayu-fish, Tsukiji Shokan, 43-45 (2016)

13. M. Hyodo, Y. Takemon, T. Sumi, Proceedings of International Conference on Fluvial Hydraulics (River Flow 2014)

14. Tenryu River Fisheries Cooperative, Report of Ayu-fish population surveys in the Tenryu River, 2006-2008, 2009-2011 (In Japanese)

15. S.S. Jia, Y. Wang, Journal of Hydraulic Engineering, ASCE, 125(9), 924-933 (1999)

16. W. Wu, J. Hydraulic Eng., ASCE, 130(10), 1013-1024 